\title{
THE ACCEPTANCE OF SUSTAINABLE FOOD CONCEPT: A QUALITATIVE EXPLORATION IN STENDEN UNIVERSITY HOTEL, THE NETHERLANDS
}

\author{
Sia Tjun Han ${ }^{1 *}$, Wahyuniwati Wahyudi² \\ ${ }^{1,2}$ Petra Christian University, Surabaya, Indonesia \\ *Corresponding author; Email: tjunhan@petra.ac.id
}

\begin{abstract}
As customers concern more about the environment, sustainable food demands, which are locally produced, organic, seasonal, and vegetarian or semi-vegetarian, are increasing. Besides, Theory of Planned Behavior (TPB) explains that behavior is guided by intentions with the factors of attitude, subjective norm, and perceived behavioral control to predict food choices; food purchasing habits and intake; and attitudes and preferences. Therefore, the research purpose is to examine customers' acceptance of The Netherlands restaurant implementing sustainable food concept using TPB. Data analysis of 10 semi structured interviews shows that the customers of Restaurant NL are more likely guided by external factors of subjective norms: work related dine-in; others' encouragement to eat more healthy and more responsibly, as the intentions are to have sustainable benefits.
\end{abstract}

Keywords: Sustainability concept in the food industry, planned behavior, Dutch cuisine.

\section{Introduction}

As customers become more concern about the environment, the demand for sustainable food concept restaurant increases. Restaurateurs become eager to walk an extra miles toward sustainability of organic food, seasonal products, vegetarian or semi-vegetarian menu, and local production. Sustainability is becoming more popular and getting all the attention, trying to raise public interest to have more responsible consumption behavior. Besides, escalating consumers' awareness in sustainable food production and consumption raises the potential impact of sustainability considerations on consumer purchase decisions, and the potential role of sustainability as a product attribute in consumer's evaluation of products (de Boer, Helms, \& Aiking, 2006). Sustainable consumption is based on a decision-making process that takes the consumer's social responsibility (animal welfare, environment, fair trade) into account in addition to individual needs (taste, price, and convenience) (Meulenberg, 2003).

Besides, Theory of Planned Behavior (TPB) recommends that a person's behavior is guided by his or her intentions (Ajzen, 2002). Factors which influence intentions are attitude, subjective norm, and perceived behavioral control. According to Ajzen (2002), the stronger the intention, the more likely the behavior is to occur. A previous research by O'Connor and White (2010) was to determine Australian consumers' willingness to try functional foods and vitamin supplements and to predict people's intentions to eat healthy. In this research, both researchers used questionnaires to discover the participants' attitudes, subjective norms, and perceived behavioral control, using the TPB. The research also tried to explore the customers' willingness to engage in free product trials. Another research was conducted in Sweden using the TPB by Gummeson, Jonsson and Conner (1997). In this research, the TPB was concluded to be useful to understand the consumers' determinants of various food choices. Gummeson et al. (1997) use the TPB to study 11-16 years old Swedish children's intentions to consume on certain healthy versus unhealthy breakfast choices. They determined that attitudes were primarily a good predictor of intentions. Furthermore, in some cases, the subjective norm could be used to predict intentions, and only in a limited number of cases they found that perceived behavioral control could predict intentions (Gummeson et al., 1997)

Researches on the factors which influence decision-making and intention to buy or use have been done many times. The Theory of Planned Behavior (TPB) proposes that one person's behavior is guided by his or her intentions (Ajzen, 2002). Factors in the TPB which influence intentions are attitude, subjecttive norm, and perceived behavioral control. Therefore, the stronger the intention, the more likely the behavior is to occur. Ajzen's Theory of Planned Behavior (TPB) has been used in researches about eating behavior to predict food choices, food purchasing habits and intake, attitudes and preferences for organic food, and fair trade products consumption (Chen, 2007; Ma, 2007). However, there is still no research that has been done until this research is being con- 
ducted to examine customers' acceptance of sustainable food concept implemented on an educational dining facility in The Netherlands. Therefore, the purpose of this research is to understand customers' acceptance of an educational dining facility implementing sustainable food concept in The Netherlands using the TPB.

Numerous evidence showed that customers have become more concerned about the environment (Han, Hsu, \& Sheu, 2009; Mohr \& Webb, 2005; Tilikidou, 2007). Other researchers also conclud that consumers do not only prefer eco-friendly products, they are even willing to pay more (Coddington \& Florain, 1993; Laroche, Bergeron, \& Barbaro-Forteo, 2002; Ottman, 1992). This concern was responded by Albert Kooy by writing a book, The New Dutch Cuisine (Kooy, 2007). Since then, Kooy introduces the sustainable food concept to the public, which is also called the New Dutch Cuisine (NDC).

The object of this research is Restaurant NL, which is located in Leeuwarden, a city in the north of The Netherlands, in the province of Friesland. The restaurant was established in 1987 as a real world learning restaurant within a hotel school by the name of Stenden University Hotel. In 2007, Albert Kooy started to be the Executive Chef of the Restaurant NL with a new food concept. This restaurant offers Dutch menu combining $80 \%$ vegetables and fruits item with $20 \%$ meat product. Unlike many other restaurants, the main ingredients in the restaurant are preferably obtained locally, bound seasonally, and produced organically. These combinations of commitments are the foundation of what the New Dutch Cuisine stands for.

Running a restaurant had its own challenges, similar to any other businesses. One of the challenges is to fulfill the demand of the customers which meet their environmental and social responsibilities. Dining out is no longer only about enjoying the dinner, but also considering customers' environmental values. Even though costumers' interest in the sustainable food concept is growing, this does not guarantee that customers' acceptance on the New Dutch Cuisine would also be high. Moreover, there are also some concerns about reducing meat portion; the restaurant use only $20 \%$ meat instead of $80 \%$ in the menu. Thus, it could lower customers' acceptance of this healthier food concept (Schulp, Kooy, \&Cavagnaro, 2010). The biggest challenge of the restaurant is the number of customers they have.

The main problem of this research is "How the New Dutch Cuisine concept affect customers' intention to dine in Restaurant NL," which is broken down into some research questions of:
$R Q_{1}$ : How do customers perceive the food concept of Restaurant.NL?

$R Q_{2}$ : What factors in the Theory of Planned Behavior influence the intention on dining in Restaurant NL the most?

$R Q_{3}$ : What strategies can the Restaurant.NL implement to improve the acceptance of the food concept in order to attract more customers?

\section{Sustainable Food Concept in the New Dutch Cuisine}

Sustainability is defined as the process of ensuring that humanity "meets the needs of the present without threatening the ability of future generations to meet their own need" (Brundtland Commission, 1987). The term actually refers to a movement of preserving the earth's resources and creating more social, economic, and environmental balance (Brundtland Commission, 1987). Hall and Vredenburg (2003) invented the term Sustainable Development Innovation, referring to the idea that knowledge innovation is inclusive of the triple-bottom line economic, social, and environmental values (Elkington, 1997).

As food patterns are rooted in their own culture, European people, especially the North-Western Europe, are known as a meat eating society. However, recent studies show that there is a growing appreciation to the vegetarian meals right now, in respect of the animal welfare (Hoogland, de Boer, \& Boersema 2005). Responding this phenomenon, Restaurant NL is a restaurant offering a sustainable food concept of Dutch Culinary tradition with more healthy food (more vegetables and fruits, less meat), environmentally friendly product, seasonal menu, and the use of local ingredients. This New Dutch Cuisine (NDC) is about respecting and preserving the Dutch culinary traditions, health, adoring freshness of the ingredients also purity of the food taste and sustainable eating, which put environment as the central role. The NDC is also about the historical value of the dish in the Dutch Culinary, bringing back a lot of ingredients and recipe from the former colonized countries all over the world (Kooy, 2007).

Restaurant NL is the object of research by Cavagnaro and Gehrels (2009), which is being monitored for its change process. Their changes throughout the past 4 years are reducing the portion size of meat, using more vegetables, increasing the share of seasonal and local food \& beverages, when possible organic and fair trade, avoiding the use of additives and flavoring agents, and the most important thing is the return to and further development of Dutch culinary traditions (Schulp et al., 2010). 
NDC concerns about the 3 basic levels of sustainability, planet, people, and profit. For the planet, NDC promotes the awareness and commitment to use organic products, environmental friendly products, seasonal consuming, and limit excessive food mileage traveled by the food. In term of people, NDC is committed to use local suppliers; concern about public health, in this case their customers and the customers to be; and respect the Dutch culinary tradition by keeping the traditional food idea and serving it to be acceptable for International consumers. NDC also concerns about economic profit by reducing the cost of meat and dairy purchase and substituting with more organic vegetables and fruits.

\section{Theory of Planned Behavior}

Ajzen's 'Theory of Planned Behavior' (TPB) model is developed to understand the influence of people's perceptions about their own control over the situation. These conceptual models are useful in understanding the structure of some intentional behavior. TPB proposes that behavior is directly influenced by intentions. Consequently, when a person has a strong intention to complete certain behavior, he or she is more likely to execute this behavior. The theory consists of three factors that affect intentions: attitude, subjective norm, and perceived behavioral control (Ajzen, 2002). Attitude refers to a person's positive or negative belief of certain behavior. Subjective norm is a person's perceived social influence regarding a behavior. Perceived behavioral control is a person's perceived capacity to perform a behavior. According to Ajzen (2002), if attitude, subjective norm, and perceived behavioral control are strong, the intention will be strong, which will make the person to perform the given behavior. The three factors explain briefly as the following Figure 1.

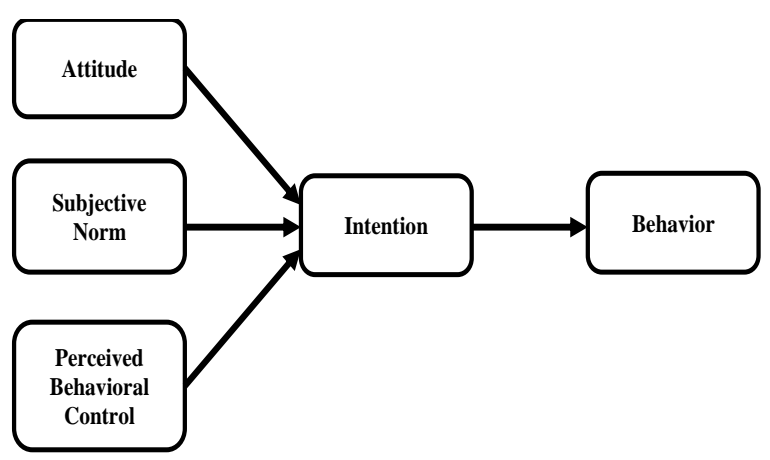

Figure 1. Theory of Planned Behavior (TPB) Source: Ajzen (2002).
Theory of Planned Behavior is widely used in studies to explain and predict food related behavior research. Results of these researchers indicated that attitudes, subjective norms, and perceived behavioral control were all positive predictors of intentions to eat healthy foods (Louis et al., 2007; Gratton, Povey \& Clark-Carter, 2007; Hewitt \& Stephens, 2007; Lautenschlager \& Smith, 2007). In addition, the attitude is found to be the strongest predictor of intention in regarding to eating behavior (Mahon, Cowan, \& McCarthy, 2006; Chen, 2007; Lautenschlager \& Smith, 2007). This is the reason to adopt the Theory of Planned Behavior by Ajzen (2002) as the predictor of the acceptance for NDC.

Understanding the reason and the purpose of the NDC concept can become a major influence for customers to dine at Restaurant NL. Dillon and Morris (1996) explain acceptance as the demonstrable willingness within the user group to employ innovation for the tasks it was designed to support. In this research, the demonstrable willingness of the customers is defined as to understand, respect, use, and commit to the NDC concept of the Restaurant NL.

\section{Research Method}

This research is a qualitative research in the forms of exploratory study to answer the how question and a case study to investigate a contemporary phenomenon within its real-life context (Yin, 2003). This study is conducted also to examine social and cultural phenomenon (Myers, 1997) about the concept of NDC in the context of sustainable food concept restaurant. To get a better knowledge of customers' acceptance of sustainable food concept restaurant, in-depth interviews using semi-structured questions were used. A series of questions were developed from the literature review on NDC concept, sustainable food concept restaurant, and the concept's acceptance. The respondents are 10 customers of Restaurant NL and have some backgrounds on food and beverage industry. The data are analyzed using content analysis, including behavior, attitude, subjective norms, and perceived behavior control with the questions of "what is sustainable food concept" and "how is NDC perceived", as well as beliefs about perceptions of sustainable food concept held by others (friends, family, etc.), beliefs about outcomes associated with frequent sustainable food consumption, and beliefs about control over consumption rates.

\section{Result and Discussion}

Based on the analysis of the interviews using $\mathrm{TPB}$, the writer finds the answers to the research problems as follows: 


\section{$R Q_{1}:$ How do customers perceive the food concept of Restaurant NL?}

Most of the interviewees could mention the keywords associated with sustainable food concept in Restaurant.NL, like the 80-20 rule, more vegetables, less meat, seasonal, organic, Dutch food and unique, as they agreed that the restaurant is sustainable in its food concept with no doubt of the concept improvement. This is the proof that the inner circle of the restaurant customers had been educated enough about the concept. All of them are aware that the restaurant serves Dutch food presented in a modern way, using new techniques, combining both ingredients and cooking methods from all over the world, especially from Asia, Africa and the Middle East with seasonal ingredients which are advantageous and cheaper. The food is assumed to have the correlation with the Dutch Culture. The interviewees also explain how the Dutch always try to get the good quality in everything for the lowest price they could find. In addition, it is also good for the environment as it uses less fossil energy to grow vegetables, fruits, and food ingredients which are naturally grown.

According to the theory, sustainability is becoming more popular and getting all the attention, trying to raise public interest to have more responsible consumption behavior. Escalating consumers' awareness in sustainable food production and consumption raises the potential impact of sustainability considerations on consumer purchase decisions, and the potential role of sustainability as a product attribute in consumer's evaluation of products (de Boer et al., 2006). Further, sustainable consumption is based on a decision-making process that takes the consumer's social responsibility (animal welfare, environment, and fair trade) into account, in addition to individual needs (taste, price, and convenience) (Meulenberg, 2003).

The findings are in line with the theories that the customers of the restaurant are already familiar with the concept of sustainable food and also the benefits of consuming it. They can recognize the concept as the menu is combined with new cooking techniques, but the food concept still follows the Dutch tradition of getting good quality with good prices.

The uses of locally grown, organic, seasonally bound and typical Dutch plants are recognized by most of the interviewees, in which the food is exceptional yet exciting. The dish is still fresh with a nice texture. To feed human beings with vegetables is taking less time to produce than meat since it takes longer for animals to be ready for food than vegetables. Besides time, energy is another consideration of choosing vegetables; the energy needed to raise animals is a lot more than what is needed for growing plants. Animal welfares also need to be considered, for not to have the animals grown in the way that they are ill-treated. The animals should not be over-harvested or over-fished, also not be taken when they are in the reproduction period.

Besides, food patterns are rooted from the culture, as European people, especially the north-western Europe, are known as the meat eating people. However, recent studies show that there is a growing appreciation to the vegetarian meals, as in respect of the animal welfare (Hoogland et al., 2005). The findings are in line with the theory that the customers changed their mindsets from meat eating habit to more vegetable consuming because of the concerns of animal welfare and also energy and time-saving.

In terms of the portion size, the food serving is commented to be smaller portions compared to other restaurants by most interviewees. The customer expectations to see regular portion meat or fish should be grasped by the restaurant in general, and by Albert Kooy in particular. New customers are astonished or feel like being tricked with the portion. Therefore, the interviewees suggest the restaurant should be more flexible about the portion size. In fact, the restaurant needs to explain for the first time visitors about the food concept, the portion size, and the reason for applying the concept to manage expectation. Because when the customers see the menu, the expectation comes. When the restaurant does not meet the customer expectation, they tend to be disappointed. Interviewees precisely explain the word "surprising" to describe the experience which is sometimes good but sometimes not. Further, it needs more menu variations in some periods of time. Besides, the word "sustainability" is a name dropping in terms of marketing since sustainability is not yet founded generally as a common term.

\section{$R Q_{2}:$ What factors in the Theory of Planned Be- havior influence the intention on dining in Restaurant NL the most?}

Most of the interviewees come to the restaurant for business purposes. Few of them come for their personal preference to adopt healthy life. Sometimes the restaurant' guests are also the hotel guests and university staff members who dine in this restaurant because of its easy access. Since most of the reasons to come to the restaurant are for business, they don't need to pay for the food by themselves. However, some of the interviewees deliberately come to Restaurant NL with the willingness to pay for their own 
meal, in which it is categorized as loyal customers of Restaurant NL because that shows appreciation toward the food concept.

Based on the previous researches, consumers do not only prefer eco-friendly products, they are even willing to pay more (Coddington \& Florain, 1993; Laroche, Bergeron, \& Barbaro-Forteo, 2002; Ottman, 1992). The findings are in line with the theories that the customers of the restaurant came to have sustainable food as eco-friendly products and showed the appreciation to pay more in order to get healthy food with sustainable food concept.

Even though the menu is not particularly a vegetarian menu, some interviewees like to go there because of the vegetable menu. The way the food prepared and served is unique and different from other restaurants as it is better in presentation, taste, value of money and Dutch menu. The food served in the restaurant is a combination of many ingredients and cooking methods from all over the world, such as the flavor and aroma from the spices of Asia with the use of wok and Chinese cooking methods.

Moreover, the idea in defining sustainability from one to other interviewees is diversed. The interviewees mention the key words of sustainability which are people, planet and profit with the expressions of "good for them" (human), "good living", "well of the planet", "living the earth without damaging", "people-profit-planet", "future generation", "natural resources", "permanence", and "better world". The interviewees consider the food concept of Restaurant.NL as a sustainable food concept. It is considered beneficial for personal, social, ecological and economic subjects.

According to the theory, Pollan (2009) suggests that people should come back to the food which has relationships with people, health and environment. Besides, Salatin (2007) also suggests that "good" food in the end will rot. Both Salatin (2009) and Pollan (2007) suggest eating only food that will rot. The findings are in line with the theory that the food served in the restaurant always follows that rule of good food, as the main ingredients of the food are vegetables that should be fresh every day and will rot before the day changes. The food concept will support the good living with the food which is good for humans and the planet, as people may save the planet by producing seasonal and natural food.

In terms of personal benefits, the food concept gives benefits to health. The health issue is one of the most important deliberations of the food concept. For social benefits, restaurateurs can concern about others to use fair trade products, for example buying coffee, tea, or cocoa from reliable sources pays with fair prices to the farmers, so the farmers could have a better standard of living.

Meat plays a very important role in the North America and European consumers. Nevertheless, in the Netherlands (FAO, 2004) this habit is because meat is considered to be nutritious and healthy. In fact, the consumption of meat has already embedded in the Western culture (Elzerman, Hoek, van Boekel, \& Luning 2011). This form of consumption is considered to be very unsustainable and also unhealthy. This is the reason that the New Dutch Cuisine promotes eating less meat and more vegetables. In Restaurant NL, the customers will not have a large portion of meat with protein and carbohydrate dishes aside. Customers will be indulged with smaller meat portion (approximately 80 grams) that will be served as a part of a dish. Kooy realizes that eating less meat is hard, but with the combination of other items in the plate, the calories and nutrients will be sufficient. Eating fruits and vegetables, plus limited qualities of nuts and seeds is considered to be the most natural and healthy food for human as adopted from the theory by Pollan (2009).

The environmental benefits from this food concept are taking consideration of the well-being of nature to the highest level. This food concept is making balance for not exhausting the planet while consuming foods. Choosing reliable suppliers and local farmers are to show the appreciation and commitment to keep the food miles as low as possible to save fossil fuel for delivery. Taking care of the planet means to take care of livings on Earth.

Numerous evidences show that customers have become more concerned about the environment (Han, Hsu, \& Sheu, 2009; Mohr \& Webb, 2005; Tilikidou, 2007). The findings are in line with the theory as the findings show that customers of the restaurant decide to have sustainable food taken from local farmers in order to fulfill the environmental needs of saving fossil fuel for the future generation because of shorter distance to save the planet from more pollution while delivering food.

The economic benefits of this food concept are for producers, sellers, and consumers. For the producers, they will be appreciated with the fair price. For the sellers, they will have the profit from making business with the consumers. For the consumers, they will get the quality that they pay. Buying seasonal products is always cheaper in the season, and that reduces the food cost. Using less meat by having less common cuts, with addition of large amount of vegetables is still profitable rather than serving the 
dish in a regular way. The price of organic vegetables will not be more expensive than regular portions of meat. Another economic benefit from this food concept is the use of local products. While buying local products, less fossil fuel is being consumed. The price of fossil fuel is almost impossible to be lower, which makes it more expensive when transporting products from far away distance.

Besides, sustainable food is taken from the origin countries as the raising awareness and interest in local economies, due to food costs and the increasing carbon footprint size of the food production chain (Pollan, 2009). This awareness brings Kooy to the commitment to use only local food product. He understands it is sustainable to get every single of these products from its own grower. However, the accumulated food miles of all the food products will be huge. This is the reason of choosing few particular food suppliers to provide him with the food products, as considered to be more sustainable.

Discussing about subjective norms, many outside people support the interviewees to dine at Restaurant NL, and most of the interviewees mention their families, friends and people who are doing business with the interviewees supported them to dine at Restaurant NL. Some of the interviewees are already self-motivated to live and to have healthy eating habit. This shows a good sign that the customers of Restaurant NL buying intention are based on their subjective norms.

Moreover, a research conducted in Sweden using the TPB by Gummeson, Jonsson and Conner (1997) proves that is useful to understand the consumers' determinants of various food choices. As well, Gummeson et al. (1997) used TPB to study 11-16 years old Swedish children's intentions to consume on certain healthy versus unhealthy breakfast choices. They determined that attitudes are primarily a good predictor of intentions. Furthermore, in some cases the subjective norm could be used to predict intentions, and only in a limited number of cases they found that perceived behavioral control could predict intentions (Gummeson et al., 1997). In this research, the findings show that by using TPB, the exploration of the attitude can be done effectively with the results that the consumers are driven by the subjective norms to consume sustainable food, in which they got supports from others to eat more healthy and responsibly. Some also follow the subjective norm to have healthy eating habit. These findings are in line with the idea by Gummeson et al. (1997) that attitudes can be used effectively as good predictors of intentions to make decisions in consuming food as being driven more by subjective norms than perceived behavioral control.

\section{$R Q_{3}$ : What strategies can the restaurant imple- ment to improve the acceptance of the food Concept in order to attract more custo- mers?}

To answer the third research question about how to attract more customers, the main problem that the restaurant struggles is occupancy. Some inputs from the interviewees can be used to help the restaurant. It is very obvious that the promotion is not effective enough to bring customers to dine at Restaurant NL. The promotion effort is too limited or it focuses too much on the existing guests. There is no hotel or restaurant advertisement within the city of Leeuwarden. Restaurant NL is not exposed and viewed as a restaurant from the outside world and it was viewed as a part of the school. Albert Kooy needs to improve his existence in culinary industry in order to give impact on the awareness of the Restaurant. He is famous for being top level chef with his concept and his book, yet he has to go further with his food concept in the restaurant and explain it better to the public. A good way to start is to do some promotion on local magazine or newspaper.

Moreover, another feedback about the concept is the local aspect of the ingredients; the restaurant should be more flexible about it. Then, the food serving is too slow. This is because the dishes are sometimes too difficult for the students. The Practical Instructor should teach the students in a better and effective way. The school needs to create consistencies in service and food production. When it comes to the service, sometimes customers feel overwhelmed by the number of servers standing and watching them eat. Restaurant NL could use the technology to give better service to their customers. This can be done by utilizing the database from the customer profile, which can be gathered by the reservation department. By doing it this way, certain customers with special needs can be accommodated. The treatment will lead to customer satisfaction, and then loyal customers.

Furthermore, Restaurant NL needs to target local customers. First of all, the target is the people who understand about the new food concept, since they would like to come and to appreciate the food concept by coming more often and adopting the concept of healthy eating habit for their own diet and also those who care about animal welfare. Secondly, people who live surrounding the restaurant/school should be targeted, not only because of easy access, but also of 
good price for good quality of food. Thirdly, women could be the potential market, since they care more about their and their family's health, so women are potential to accept the food concept more positively. Fourthly, business people with higher income and higher education level usually are more concerned about their own health, as this is supported by one of the interviewees' statement that many rich and highly educated people tend to go to farmer markets to buy organic vegetables and fruits. Fifthly, the parents and family of the students must be potential customers to seek. Since they are visiting the students, they stay at the hotel of the school and dine in the Restaurant NL. Finally, since the hotel school is located next to the NHL University and near with Van Hal University, people from those institutions are also potential to come having lunch or dinner in the restaurant. This is also supported by the cooperation between these two universities with Stenden University in many occasions and agreements.

\section{Conclusions and Implications}

In conclusion, the customers in the Restaurant $\mathrm{NL}$ are sustainable consumers as they choose to have sustainable food because of the awareness of social responsibility, such as animal welfare, environment, and fair trade, as additional to individual needs of taste, price, and convenience. The customers agree to adopt the sustainable food concept which is unique as the combination of new cooking techniques and ingredients all over the world, advantageous, and valuable in terms of saving time, money and energy. The intention of the customers is mostly driven by the external factor of subjective norms, including business purposes to dine in, others' encouragement to eat more healthy and responsibly in order to get sustainable benefits including personal, social and environmental benefits. The inputs for further application of the sustainable food concept to attract more customers are the improvement of advertisement, service speed, and flexibility of food portion and technology uses; and also setting up the locals to be potential customers.

\section{References}

Ajzen, I. (2002). Icek Ajzen: Theory of planned behavior. Retrieved September 21, 2011, from http://peo ple.umass.edu/aizen/tpb.html.

Brundtland Commissioan (1987). Our common future. Oxford: Oxford University Press.

Cavagnaro, E. \& Gehrels, S. A. (2009). Sweet and sour grapes: Implementing sustainability in the hospitality industry: A case study. Journal of Culinary Science \& Technology, 7(2, 3), 181195.

Chen, M. (2007). Consumer attitudes and purchase intentions in relation to organic foods in Taiwan: Moderating effects on food-related personality traits. Food Quality and Preference, 18, 10081021.

Coddington, W. \& Florain, P. (1993). Environmental marketing: Positive strategies for reaching the green consumer. New York: McGraw-Hill.

De Boer, J., Helms, M., \& Aiking, H. (2006). Protein consumption and sustainability: Diet diversity in EU-15. Ecological Economics, 59, 267-274.

Dillon, A. \& Morris, M. G. (1996). User acceptance of information technology: Theories and models. In M. Williams (Ed.), Annual review of information science and technology, 31 (pp. 3-32). Medford, NJ: Information Today.

Elkington, J. (1997). Cannibals with forks: The triple bottom line of $21^{\text {st }}$ century business. USA: New Society Publisher.

Elzerman, J. E., Hoek, A. C., van Boekel, M. A. J. S., \& Luning, P. A. (2011). Consumer acceptance and appropriateness of meat substitutes in a meal context. Original Research Article, 22, 233-240.

FAO (2004). Food and agriculture organization of the United Nations. Vialedelle Terme di Caracalla, 00100. Rome: Italy.

Gratton, L., Povey, R., \& Clark-Carter, D. (2007). Promoting children's fruit and vegetable consumption: Interventions using the theory of planned behavior as a framework. $\mathrm{Br} J$ Health Psychol, 12, 639-650.

Gummeson, L., Jonsson, I., \& Conner, M. (1997). Predicting intentions and behavior of Swedish 10-16 years old at breakfast. Food Quality \& Preference, 8(4), 297-306.

Hall, J. \& Vredenburg, H. (2003). The challenges of innovating for sustainable development. Sloan Management Review Fall, 45(1), 61-68.

Han, H., Hsu, L. T., \& Sheu, C. (2010). Application of the theory of planned behavior to green hotel choice: Testing the effect of environmental friendly activities. Tourism Management, 31(3), 325-334.

Hewitt, A. M. \& Stephens, C. (2007). Healthy eating among 10-13 year old New Zealand children: Understanding choice using the Theory of planned behavior and the role of parental influence. Psychol Health Med, 5, 526-35.

Hoogland, C. T., de Boer, J., \& Boersema, J. J. (2005). Transparency of the meat chain in the light of food culture and history. Appetite, 45, 15-23. 
Kooy, A. (2007). The New Dutch Cuisine. Zutphen, Kunstmag: KMPublishers.

Lautenschlager, L. \& Smith, C. (2007). An evaluation of inner-city youth garden program participants' dietary behavior and garden and nutrition knowledge. Journal of Agricultural Education, 49(4), $11-24$.

Laroche, M., Bergeron, J., \& Barbaro-Forleo, G. (2001). Targeting consumers who are willing to pay more for environmentally friendly products. Journal of Consumer Marketing, 18(6), 503-20.

Louis, D. N.,Ohgaki, H., Wiestler, O. D., Cavenee, W. K., Burger, P. C., Jouvet, A., Scheithauer, B. W., \& Kleihues, P. (2007).Targeting consumers who arewilling to pay more forenviron mentally friendly products. Journal of consumer marketing, 18, 503-520.

Mahon, D., Cowan, C., \& McCarthy, M. (2006). The role of attitudes, subjective norm, perceived control and habit in the consumption of ready meals and takeaways in Great Britain. Food Quality and Preference, 17(6), 474-481.

Meulenberg, M. (2003). Consumenten burger, betekenisvoor de markt van land bouw product en envo edings middelen (Consumer and citizen, meaning for themarket of agricultural products and food products). Tijdschri ftvoor Sociaal Wetens chappelij konder zoek van de Landbouw 18 (1), 43-56.
Mohr, L. \& Webb, D. (2005).The effects of corporate social responsibility and price on consumer responses. Journal of Consumer Affairs, 39(1), $121-47$.

Myers, M. D. (1997). Qualitative research in information system. MIS Quarterly, 21(2), 241-242.

O'Connor, E. L. \& White, K. M. (2010). Willingness to trial functional foods and vitamin supplements: The role of attitudes, subjective norms, and dread of risks. Food Quality and Preference, 21(1), 75-81.

Ottman, J. A. (1992). Environmentalism will be the trend of the '90s. Marketing News 26(25), 13.

Pollan, M. (2009). Food rules: An eater's manual. New York: Penguin.

Schulp, J.A., Kooy. A., \& Cavagnaro, E. (2010). Toward a sustainable f\&b management-work in progress. Proceedings of the EuroCHRIE Conference (25-27 October 2010 in Amsterdam), EuroCHRIE (digital publication).

Salatin, J. (2007). Everything $i$ want to do is illegal: War stories from the local food front. Swoope, VA: Polyface, Inc.

Tilikidou, I. (2007). The effects of knowledge and attitudes upon Greek's pro environmental purchasing behavior. Corporate Social Responsibility and Environmental Management, 14(3), 121-134.

Yin, R. K. (2003).Case study research: Design and methods, ( ${ }^{\text {rd }}$ Ed.). Thousand Oaks, CA: Sage Publisihing. 